\title{
A família (con)vivendo com a mulher/mãe após a mastectomia
}

\author{
Life in families with wives and mothers after mastectomy
}

\author{
Patricia Isabel Bervian' e Nara Marilene Oliveira Girardon-Perlini²
}

\section{Resumo}

Considerando que o adoecimento de um dos membros de uma família pode refletir-se nos demais e que a realização de uma cirurgia mutiladora, como a mastectomia, pode comprometer a imagem e as relaçōes familiares, buscouse, com este estudo, compreender como é para a família ter em seu meio a mulher/mãe que realizou mastectomia. Este estudo é de abordagem qualitativa, descritiva. Os dados foram coletados por meio de entrevistas a familiares (maridos e/ou filhos) de mulheres mastectomizadas que participam de um grupo de auto-ajuda. O processo de análise e interpretação dos dados foi baseado na análise de conteúdo. Como resultado, obteve-se uma categoria, cujo tema é a doença como forma de promover mudanças e fortalecer os laços familiares, destacando o impacto do diagnóstico, no qual os familiares e a mulher sentem-se chocados e abalados emocionalmente, sendo necessário tempo para se reestruturarem, tomarem decisōes e enfrentarem o diagnóstico; em que a família procura elaborar estratégias para reorganizar a estrutura familiar, fazendo com que esta permaneça unida, busque forças e esperança a fim de superar os momentos de incertezas.

Palavras-chave: Neoplasias, Família, Mastectomia, Enfermagem, Enfermagem familiar.

\section{Abstract}

Considering that illness in one member of the family can affect the others, and that mutilating surgery like mastectomy can affect the family's self-image and relations, this study sought to understand how families cope with living with a wife or mother who has undergone mastectomy. The methodological approach was qualitative and descriptive. Data were collected through interviews with family members (husbands and/or children) of post-mastectomy women who were participating in a self-help group. The process of analyzing and interpreting the data was based on content analysis. This resulted in a category whose theme is the disease as a way of promoting changes and strengthening family ties, highlighting the impact of the diagnosis, where the family and woman feel emotionally shocked and shaken and need time to regroup, make decisions, and face the diagnosis; in which the family seeks to elaborate strategies to reorganize the family structure in order to stay united and seek strength and hope to overcome moments of uncertainty.

Key words: Cancer, Family, Mastectomy, Nursing, Family nursing.

\footnotetext{
${ }^{1}$ Enfermeira graduada pela Universidade Regional do Noroeste do Estado do RS -UNIJUÍ. Atua no Programa de Saúde da Família de Pejuçara/RS. ${ }^{2}$ Enfermeira. Mestre em Enfermagem pela EEUSP. Docente do Departamento de Ciências da Saúde da UNIJUÍ.

Endereço para correspondência: NMOGP Rua José Gabriel, 359 - Centro. Ijuí/RS. CEP 98700-000. E-mail: nara.girardon@unijui.tche.br
} 


\section{INTRODUÇÃO}

Com base em informações do Instituto Nacional de Câncer ${ }^{1}$, a neoplasia da mama continua sendo a maior causadora de óbitos entre as mulheres, sendo que dos 467.440 novos casos de câncer com previsão de serem diagnosticados em 2005, o câncer da mama foi o segundo mais incidente entre a população feminina, sendo responsável por 49.470 casos novos.

Um dos métodos mais utilizados para o tratamento do câncer da mama é a mastectomia, uma cirurgia mutiladora que visa remover todo o tumor visível e que pode ter como conseqüência problemas físicos e psicológicos. A resposta à mutilação é individual e pode estar relacionada a fatores como idade, auto-admiração, estado emocional e situação sócio-econômica. Como em qualquer mutilação, a mastectomia requer, além dos cuidados próprios da cirurgia, apoio emocional, objetivando uma melhor compreensão, interação, adaptação e aceitação da auto-imagem. ${ }^{2}$

Estudos realizados com mulheres indicam que ao receber o diagnóstico de câncer da mama, a mulher começa a enfrentar um momento difícil em sua vida, passando a vivenciar três etapas diferentes e complexas: primeira, o diagnóstico de estar com câncer, palavra carregada de sentimento negativo em nossa sociedade; segunda, a realização de um tratamento muito longo e agressivo, muitas vezes, com necessidade de retirada parcial ou total da mama para restabelecimento da saúde; e, a terceira, a aceitação de um corpo marcado e a convivência com essa imagem. ${ }^{3}$

Em concomitância, como ocorre muitas vezes, a família geralmente não está preparada para enfrentar o adoecimento e para suportar o sofrimento de seu familiar, e com isso acaba contribuindo para que este processo se torne mais sofrido para a mulher. A família precisa tanto de apoio e de orientação quanto a paciente. Não existe experiência pior para uma família, que a faça ficar confusa, sentindo-se inadequada, precisando de compaixão e compreensão, do que assistir a uma pessoa de quem se gosta sofrer de uma doença fatal. ${ }^{3}$

Os maridos ou companheiros podem ter reações difíceis frente à doença e à cirurgia. $\mathrm{Na}$ maioria dos casos, a reação dos parceiros diante da mastectomia depende da reação que a mulher tenha: se ela puder aceitar a amputação da mama, poderá influenciar o marido a também aceitar o fato e melhorar o relacionamento. $^{2}$

Ao receber o diagnóstico de câncer da mama, a mulher precisará do apoio familiar, e é necessário que a família não esqueça suas próprias necessidades, sendo solidária, não permitindo que a paciente se deixe vencer pela doença. $\mathrm{O}$ afeto familiar permite à mulher manter uma certa estabilidade para lutar contra a doença. Sendo assim, consegue suprir suas carências emocionais, alcança uma melhor aceitação e orientação comportamental. ${ }^{4}$ Neste sentido, nenhuma pessoa vive no mais completo isolamento, sem ser influenciada pelo meio em que vive e pelas pessoas que a rodeiam. ${ }^{3}$

Além disso, entendemos que a família é um sistema interligado e que cada um de seus membros tem influência sobre o outro, sendo que o adoecimento de um dos integrantes, neste caso da mãe/esposa, tem reflexos no comportamento e no estado emocional e até biológico dos demais.

Esta concepção é baseada na Teoria Geral dos Sistemas apresentada por Von Bertalanffy, em 1936, cujos conceitos são muito empregados não só na área tecnológica e organizacional, mas também na biologia, nas ciências sociais, do comportamento e filosofia, sendo utilizada por muitos pesquisadores para entender e explicar o funcionamento das famílias. De acordo com esta teoria, um sistema pode ser definido como um complexo de elementos em interação, interação essa de natureza ordenada, que não se limita aos sistemas materiais, mas a "qualquer todo constituído por componentes em interação". ${ }^{5}$ Um sistema é parte de um todo, formado pela união de várias partes (subsistemas), sendo geral para as partes que o compõe e parte da composição de outro sistema mais amplo. Todas as partes de um sistema dão suporte para a integridade deste e têm a capacidade de manter um certo grau de organização em face de mudanças internas ou externas.

Os conceitos desenvolvidos na teoria proporcionam um fundamento para o entendimento da família como um sistema e cada indivíduo que a integra como um subsistema. Esses indivíduos, no entanto, também se constituem num sistema, uma vez que eles são um organismo composto por vários subsistemas (sistemas físicos e psicológicos como, por exemplo, o cardiovascular e o cognitivo). Assim, um sistema individual é portanto uma parte como um todo, tal como a família. ${ }^{6}$

Pensar família na perspectiva sistêmica, possibilitanos ver cada família como uma unidade em interação e que também ela, ao interagir com outros sistemas, configura-se em parte de supra-sistemas mais amplos.

O funcionamento da família, nesta teoria, pode ser explicado através do exemplo clássico de um móbile, que ao movimentarmos uma de suas peças, todas as demais se movimentam e se desorganizam. Com o passar do tempo ou de interferências, elas poderão se estabilizar novamente ou se manter desorganizadas. ${ }^{6}$

Do ponto de vista das famílias, entendemos que o câncer da mama e, por conseguinte, a mastectomia 
causam uma situação de desorganização entre os membros, sendo que com o passar do tempo (e este é diferente para cada indivíduo) a situação vai sendo processada, enfrentada e elaborada, possibilitando à família reorganizar-se, talvez em moldes distintos do anterior ao adoecimento, mas reconstituindo-se com base nas novas experiências e nos velhos laços que os uniam e os aproximavam, ou até não.

A realização de estudos que busquem compreender as repercussōes na família ao ter um de seus membros com câncer, em especial com câncer da mama tendo realizado mastectomia, reveste-se de importância para a enfermagem e demais áreas da saúde que interagem com esta realidade. Ao aprofundar o conhecimento das relações familiares, suas reaçôes, seus sentimentos e sua dinâmica, principalmente no âmbito da denominada família nuclear, que inclui pai, mãe e filhos, este poderá servir de subsídio para que os profissionais colaborem no enfrentamento da situação, direcionando ações que incluam aspectos relacionados à família como um todo. Para as mulheres e para os familiares (marido e filhos, em especial), parece ser fundamental a sensibilização dos profissionais, para que ofereçam cuidados também aos integrantes da família, na medida em que conhecem os dramas vividos pela estrutura familiar.

Assim, considerando os aspectos aqui apontados, a pergunta desse estudo pretende responder como é para a família ter em seu meio uma familiar (mãe/esposa) após mastectomia?, tendo como objetivo conhecer as percepções da família que tem em seu meio uma mulher (mãe/esposa) mastectomizada.

\section{CAMINHO METOdOLÓGICO}

O presente trabalho trata-se de uma pesquisa de abordagem metodológica qualitativa exploratória, realizada no município de Santa Rosa, situado na região Noroeste do Estado do Rio Grande do Sul, o qual possui um total de 65.863 habitantes.

Optamos por realizar o estudo nesse município por ser considerado um precursor e um destaque na área de Saúde Pública na região, e por haver um grupo de mulheres mastectomizadas já constituído, o que facilitou o acesso aos seus familiares.

O grupo "Mama Viva" é coordenado pela equipe da Unidade Básica de Saúde (enfermeira e médica) onde ocorrem os encontros. É oferecido a usuários de toda rede de saúde do município. Dele podem participar mulheres que tenham realizado mastectomia, familiares e também pessoas da comunidade em geral. Os encontros são mensais, no turno da tarde, e têm por finalidade a troca de informações e experiências sobre a doença e o adoecimento, e prestar apoio às mulheres mastectomizadas. O grupo é aberto e dele participam, em média, 15 pessoas.

Neste estudo, participaram maridos e filhos de mulheres que participam desse grupo e que se submeteram à mastectomia, independente do tipo de cirurgia realizada (parcial ou radical). Como critério de inclusão, definimos que os filhos tenham idade acima de 18 anos, pois nesta faixa etária, além de maioridade legal, têm, a priori, maturidade para refletir e responder a questionamentos desta natureza; que o marido conviva com a mulher; e que concordem em participar do estudo. Considerando estes critérios, constituem a casuística do estudo três maridos, dois filhos e uma filha, totalizando seis pessoas.

Para obter as informações, utilizamos a entrevista aberta com uma pergunta norteadora: "Como é para sua família ter a mãe/esposa mastectomizada? Fale à vontade sobre isto". Para registro das informações, utilizamos o gravador.

$\mathrm{Na}$ fase de coleta dos dados, inicialmente, participamos de reuniões do grupo "Mama Viva", ocasião em que nos apresentamos aos presentes e explicamos os motivos de nossa participação, bem como dos objetivos de nosso trabalho e o interesse em estar contatando com os familiares das participantes. Foi assegurado publicamente o direito de recusa em fornecer o endereço dos familiares, sem qualquer prejuízo.

$\mathrm{Na}$ seqüência, por meio de telefonemas, contatamos com os familiares para explicar sobre os objetivos do estudo e convidá-los a participar do mesmo. Aos que aceitaram, foram marcados data e horário convenientes para realização das entrevistas, as quais ocorreram nas residências dos mesmos.

Contatamos com nove pessoas que poderiam compor os sujeitos da pesquisa. Destas, três se recusaram a participar. A justificativa utilizada para a recusa foi a de que não se sentiam preparadas e não gostariam de falar sobre o assunto nesse momento.

$\mathrm{Na}$ realização das entrevistas, foram respeitados os princípios éticos que regem uma pesquisa envolvendo seres humanos, segundo a Resolução 196/96 do Ministério da Saúde. ${ }^{8}$ Deste modo, antes de darmos início às entrevistas, foi explicado o objetivo da pesquisa, garantindo-se o anonimato do informante pelo uso de codinomes, de deuses da mitologia grega, bem como a liberdade de desistir do estudo a qualquer momento, se assim o desejasse. Foi lido o Termo de Consentimento Livre e Esclarecido (TCLE), para ser assinado pelos entrevistados.

O projeto de pesquisa foi apreciado e aprovado pelo Comitê de Ética em Pesquisa (CEP) da Universidade Federal de Santa Maria (UFSM) de acordo com o 
expediente no 001671/2004-72 e registro CEP/UFSM: 009/2004.

Como forma de proceder à análise dos dados, orientamo-nos pelos passos metodológicos sugeridos por Minayo, que propõe a ordenação, classificação e análise final dos dados.?

\section{APRESENTAÇÃO E ANÁLISE DOS DADOS}

Considerando o objetivo proposto para esse estudo, procuramos, através dos significados expressos na fala dos entrevistados, agrupá-los e, por semelhança, elaboramos uma categoria de análise, cujo tema é "A doença como forma de promover mudanças e fortalecer os laços familiares", que aborda o impacto e o enfrentamento do diagnóstico pela família na ótica de maridos e filhos.

\section{A doença como forma de promover mudançase fortalecer os laços familiares}

$O$ câncer da mama é a neoplasia maligna que mais atinge as mulheres, sendo que o índice de mortalidade é elevado entre as mesmas. Frente a isto, pensamos no quanto deve ser difícil, para a mulher e para sua família, descobrirem-se com este diagnóstico. Esta afirmação baseia-se no impacto do diagnóstico e na reação manifestada pelos familiares participantes desse estudo quando souberam que sua mãe ou mulher tinha esse diagnóstico. A reação foi descrita como "um choque". Segundo o dicionário Aurélio, choque tem sua definição como sendo um abalo emocional. ${ }^{10}$ No entanto, outros autores definem choque como sendo um sentimento de torpor, de atordoamento e incompreensão, seguido, geralmente, por um período de demonstração do sofrimento e desespero. ${ }^{11}$ Esta palavra "choque" foi utilizada pela maioria dos entrevistados para referir-se ao impacto causado sobre a família, quando da confirmação do diagnóstico, evidenciando ser um momento em que as famílias são surpreendidas e sentem-se abaladas com a doença e com a perspectiva que ela representa. Esta situação vivenciada provoca desequilíbrio emocional entre os membros da família, como pode ser verificado nos depoimentos a seguir: Para eles, o pai e os outros irmãos, também foi uma barra muito pesada, um choque, pegou e chegou e veio a doença (Hermes - filho).

Foi um choque. Eu sou o primeiro filho e minha irmã quando ficou sabendo não parava de chorar, "a mãe vai morrer, a mãe vai morrer". Nós a convencemos que não é bem assim. (Apolo - filho)

Desde o começo, quando apareceu, foi notado que tinha o nódulo. Foi uma insistência de quatro anos para ela tomar esta decisão. Inclusive ela brincava com a situação... (silêncio) "deixa meu câncer". E se deixava um mês, se deixava outro, um dia, um ano e quando se viu passou este tempo. Até que a insistência foi maior, fui pra cima, até que ela resolveu decidir, até que ela resolveu fazer o tal exame, aí apareceu positivo. Então, para a família foi um choque... (silêncio) Uma coisa que mexeu com todo mundo, ela entrou num pânico medonho e não só ela, mas principalmente ela... (Adônis - marido).

A revelação do diagnóstico provoca nos familiares um impacto emocional que necessita de tempo para ser elaborado. O impacto pode ser descrito como um abalo moral causado nas pessoas por um acontecimento chocante ou impressionante, uma impressão muito forte, muito profunda causada por efeitos diversos ${ }^{10}$, podendo estar, neste caso, relacionado ao medo do desconhecido que envolve a doença, da perspectiva de sofrimento e também de morte.

A família enfrenta e enfrentará muitas ocasiões difíceis, novas ou não, durante o curso da doença, porque essa situação é própria da patologia crônica, fazendo parte da vivência da família. Neste período de espera até a decisão pela busca de diagnóstico, a mulher e também o(s) familiar(es) que compartilha(m) do fato, passam, muitas vezes, por conflitos psicológicos e enfrentam uma séria crise emocional, vivendo momentos de dúvidas, insegurança e incertezas.

Deixar a decisão de iniciar o tratamento para a mulher pode, a princípio, ser uma forma de ajuda para possibilitar que esta elabore a situação e possa fortalecerse internamente para enfrentá-la. Por outro lado, também os familiares poderão elaborar seus sentimentos e organizarem-se psicologicamente para encorajá-la e apoiá-la durante as fases de diagnóstico e tratamento. Todavia, esta conduta também necessita de tomadas de decisões conjuntas, pois pode ser difícil para a mulher neste momento posicionar-se com segurança. Assim, a participação da família no enfrentamento, tanto do ponto de vista emocional quanto prático de consultar, procurar tratamento e optar pelo tipo de tratamento são significativos para os encaminhamentos e para as relações intrafamiliares.

A indecisão e a espera para decidir pela busca de ajuda profissional, muitas vezes, estão associadas ao futuro, ao prognóstico e aos efeitos que esse tratamento irá representar para a mulher, assim como para sua família, e aos arranjos que serão necessários fazer para garantir a funcionalidade dos familiares.

Logo no início foi um choque muito grande, porque foi de repente, e como eu tenho uma filha que é médica, ao invés dela dar força, era ela a mais desesperada, que fazia nós ficar pra baixo também. Então, eu disse a ela que não é choro que vai curar a mãe, tem que dar força, coragem. 
Daí ela disse, tá bom pai, eu vou mudar...(Eros - marido).

Não é fácil aceitar um diagnóstico de câncer, não importam os conhecimentos que se tenha sobre a doença. Nesta árdua luta contra o diagnóstico de câncer, o impacto do medo do desconhecido atinge não somente o paciente, porquanto todos da família ficam naturalmente tão perturbados que não conseguem viver normalmente. ${ }^{12}$

Estudo realizado sobre a experiência de famílias que convivem com a doença crônica de criança constata que estas não esperavam que o diagnóstico fosse de uma doença séria e incurável e consideram ser esta a fase mais difícil, na qual o descontrole da situação vivida é maior ou mesmo total, pois não sabem se conseguirão continuar vivendo com o sofrimento e se terão condições para ajudar ao doente. ${ }^{13} \mathrm{~A}$ nosso ver, esta realidade é similar a todas as situações de doença crônica vivenciadas pelas famílias, independente da faixa etária do familiar acometido.

Quando a mãe chegou para me falar, eu estava deitado na minha cama, e ela me abraçou e disse assim: estou com cancer e começou a chorar e chorava, chorava... e eu disse que ia dar tudo certo... o que passou pela cabeça dela é que ela ia morrer..., mas nós estávamos sempre do lado dela apoiando (Hermes - filho).

As famílias e as mulheres sofrem no momento do diagnóstico, e o sentimento que as invade é o medo da morte. Esse sentimento é percebido pelos demais membros da família que, embora também possam estar temerosos, procuram expressar palavras de ânimo, coragem e incentivo de que a situação se resolverá satisfatoriamente. Este sentimento surge porque quase sempre o câncer está associado à morte, a uma doença sem cura, ao fim da vida.

Do momento que ela descobriu até a retirada foi um dos momentos mais dificeis para a família, pois ficamos numa apreensão muito grande para saber o resultado, mas estávamos todos conscientes do que poderia acontecer. Ai quando ela soube quase não acreditou. Nós a levamos para procurar outros médicos, mas não teve volta, teve que fazer a cirurgia (Zeus - marido).

A preocupação central da mulher e da sua família, após o diagnóstico, é a sobrevivência. Em seguida, surge a preocupação com o tratamento e as condiçôes econômicas para realizá-lo. Por fim, há preocupação com a mutilação, com a desfiguração e suas conseqüências para a vida sexual da mulher. ${ }^{14}$

Percebe-se que a família, com a doença de um de seus membros, é afetada em toda sua estrutura. Diante dessa situação, a família procura elaborar estratégias para tentar reorganizar-se e/ou manter a estrutura familiar, fazendo com que esta permaneça unida, para buscar forças e esperança a fim de superar este momento de incertezas. Assim, parte para o enfrentamento do diagnóstico.

Todos os entrevistados enfatizam que após o adoecimento da mãe/mulher a família mudou, tornandose mais unida.

...n a família começamos a nos unir mais, a dar apoio a ela... (Atena - filha) ...e a união da família melhorou cada vez mais... (Hermes - filho).

A familia mudou para melhor, o afeto é mais amplo, $o$ cuidado. Os filhos ficaram mais atenciosos e o nosso relacionamento também mudou para melhor. A gente tem mais atenção um com o outro e quando nós dois estamos bem, tudo na família também está bem (Zeus - marido).

Para a família, manter-se unida é uma condição que também possibilita recarregar suas forças para continuar sendo uma família e de preservar-se como tal. A família assume que a prioridade, neste momento, é a mãe/ esposa, e todos os membros reorganizam-se priorizando assegurar os laços familiares como forma de fortalecer e dar apoio a ela, para que não se rompa o elo entre eles, e que a família permaneça unida. De certo modo, pode-se afirmar que a união em torno da pessoa doente, com a finalidade de lutar por sua recuperação, protegêla e cuidá-la, constitui-se num objetivo comum a todos. $\mathrm{E}$ isso os une e os compromete.

Assim, como forma de manter-se como uma família e indicando a existência de um movimento intrafamiliar para o enfrentamento da situação, cada integrante busca fazer a sua parte, e esta, algumas vezes, concretiza-se em modificações de comportamentos e de atitudes.

Neste sentido, identifica-se que individualmente os entrevistados relataram aspectos em que modificaram seu comportamento como forma de proporcionar bem estar e tranqüilidade à mãe/esposa. Esta preocupação pode ser entendida como uma forma de demonstrar afeto e cuidado.

Eu antes tinha atividade e coisa. Não era muito ligado pra casa, alguma coisa ou outra. Eu sempre deixava, se eu tinha alguma coisa dizia: vou fazer amanhã, se tinha que viver um pouquinho com a família sempre dizia assim: amanhã!' Amanhãa! Se era pra ir no cinema, se era pra ir jantar fora, alguma coisa: amanhã! Amanhä! Quando eu soube desse caso (silêncio e choro)... Sabe, sempre tem aquela que parece que não tem volta... Eu mudei a minha vida, comecei a voltar para o lado da familia. Olha... (silêncio) Eu, além de marido, eu acho que mudei, além de pai, eu acho que mudei também comigo mesmo. Então, se eu até tiver que sair, eu sempre digo: mulher, vamos sair juntos, vamos naquilo juntos. Ai tu pensa, parece que tu deixou de ser aquilo que tu realmente queria ser...(Eros - marido).

Nós, na família, começamos a não fazer tanta bagunça 
e coisas que antes faziamos. Vamos dizer, eu saia bastante e chegava às 3, 4 da manhãa e a mãe não gostava muito, $e$ agora eu procuro chegar antes e não ter muito som alto, música pesada (Apolo - filho).

O impacto de uma doença cujo estigma social repercute em incertezas quanto ao prognóstico leva as pessoas a refletirem sobre a finitude humana, tanto a própria quanto a do outro. Enquanto percebe-se saudável, as relações interpessoais são, muitas vezes, banalizadas e tidas como estáveis e certas, como pode acontecer entre os membros de uma família. O tempo disponível parece infinito e a possibilidade de estar junto, sempre presente, fazendo com que a família permaneça constituída como tal sem que as diferenças, as ausências e os mal entendidos necessitem ser resolvidos. Diante da possibilidade da perda, as relações passam a ser pensadas e, muitas vezes, revisadas no sentido de reaproximação e de ver o outro além de si mesmo, nas formas que podem contribuir para o seu bem estar. Isto pode ser identificado tanto no depoimento de maridos quanto de filhos.

Mudou para melhor até, os filhos, só um mora em casa, mas os outros vinham pouco e depois disso sempre davam uma escapadinha para ficar com ela e a familia sentiu que ajudou, mas com o apoio dela também. Como eu disse antes, até aumentou o sentimento, o meio familiar melhorou, melhorou no sentido que eu até não esperava, não que estivesse ruim antes, mas melhorou, deu para melhorar e melhorou mesmo, foi um amadurecimento de todos em cima daquilo ali, foi uma coisa a mais que foi aprendida, uma coisa desconhecida que deu um conhecimento a mais, um melhoramento de coisas (Adônis-marido). Dentre as diversas formas de apoio, resultantes da reorganização da família para cuidar, os entrevistados mencionam o acompanhamento durante o tratamento quando da realização da quimioterapia, e nas internaçōes.

Depois disso, começou a quimioterapia. Era eu que ajudava em tudo que precisava, eu estava sempre lá, dando apoio...(Hermes -filho). As primeiras sessóes de quimioterapia foram horriveis (...) ela agora está fazendo a quinta e ainda está sendo ruim, mas na primeira vez ela ficou uns 3 ou 4 dias mal, dai nós comprávamos remédio, dávamos injeção...(Apolo - filho).

Todo mundo ajudava e acompanhava, tanto a avó, a tia e depois da operação veio a fase dos curativos (Adônis marido).

Com o adoecimento de um dos membros da família, torna-se fundamental o apoio prestado pelos de outros integrantes, como dos irmãos, avós, tios, primos, cunhados. Nesta fase tão delicada para a mulher, o marido e os filhos, qualquer demonstração de cuidado e atenção só virá a beneficiá-los.
Durante o tratamento quimioterápico, o relacionamento das mulheres com seus familiares, muitas vezes, vai depender de como estas percebem seu corpo, envolvendo a sua auto-estima. ${ }^{15}$ Tanto a mastectomia como a quimioterapia alteram a imagem corporal, fazendo com que isso se reflita de forma negativa na aceitação do seu "novo corpo".

A mastectomia causa alteração na auto-estima e a quimioterapia potencializa essa alteração, já que ocasiona efeitos colaterais que afetam a mulher física e psicologicamente, implicando no autoconceito e na autoimagem. Assim, as dificuldades enfrentadas diante da doença e do tratamento não atingem apenas a doente, mas a família como um todo, mudando o papel social de cada membro. A mãe que, culturalmente assume o papel de cuidadora quando alguém adoece, de protetora e provedora afetiva, em especial dos filhos, passa a ser por estes cuidada. Há uma inversão de papéis em que é necessário lidar com a situação e com as ambigüidades que a acompanham.

Depois da mastectomia, a mãe mudou bastante por causa da auto-estima dela que caiu... Teve uns problemas dela, que pegou o psicológico e que afetou... Os dois brigavam bastante, a minha mãe pensava que meu pai tinha outra e se separaram. Sem o nosso apoio eu acho que a mãe não estaria aqui conosco (Hermes - filho).

$\mathrm{Na}$ percepção desse filho, o fato de a mãe ter amputado parte de seu corpo, influenciou na sua autoestima e, em conseqüência disto, interferiu nas relações conjugais, dificultando o relacionamento e culminando com a separação. Algumas vezes, o tempo decorrido entre a notícia de que a paciente está com câncer da mama e a cirurgia é suficiente para que apareçam reações, ou para que a paciente elabore pensamentos em relação à sua mutilação, sentindo-se ameaçada a perder o marido, a se tornar objeto de piedade ou mesmo a perder sua feminilidade. ${ }^{16}$

Durante o tratamento e na reabilitação da mulher mastectomizada, o apoio que os familiares, amigos ou outras pessoas prestam é de fundamental importância, pois contribuirá de forma positiva na trajetória da mulher neste período.

Estudo sobre o enfrentamento dos familiares à imagem corporal alterada do laringectomizado indica que o apoio da família é um dos principais recursos externos do paciente, para o desenvolvimento de estratégias de enfrentamento. ${ }^{17}$ Enquanto o paciente busca alternativas para lutar contra a doença, a família tem um importante papel em apoiar ou não as mudanças que ocorrem com ele, evitando assim os fatores desnecessários. Sendo assim, como o paciente desenvolve estratégias de enfrentamento para aceitar a sua nova 
imagem corporal a família também o terá que fazer.

Então, a única coisa que ficou, quando ela fez as sessões de rádio, foi aquela parte da pele escura, queimou, ficou feio, ela chorava, então eu nunca cobrei nada dela, ficou com a estética feia, um corpo feio, uma coisa assim, sabe, se tu olhar um corpo de uma pessoa e tirar um pedaço fica aquele buraco, aquela coisa feia, eu nunca cobrei nada dela, isso seria um choque pra ela tão forte que ela ia se sentir mal, talvez ela nem iria conseguir tirar a blusa na minha frente pra não me mostrar e eu não dizer de novo que ficou feio...(Eros - marido). A família, por sua vez, também é suscetível à mudança na imagem de sua familiar, pelo menos nos primeiros tempos decorridos após a cirurgia. Todavia, fica evidente a preocupação em não magoar, ferir a auto-estima e em ser acolhedor e compreensivo diante das modificações. A alopecia, decorrente da quimioterapia, foi citada pelos familiares entrevistados como algo a modificar a imagem da familiar, porém não é manifestada como um evento que tivesse grande importância. Dois colaboradores assim referiram.

Como ela descobriu o nódulo logo no início, não necessitou tratamento quimioterápico. Por esse motivo, penso que não foi tão traumático, porque a mãe não perdeu o cabelo, já que ela é muito vaidosa (Atena - filha).

Quando chegou para fazer a segunda quimioterapia, o cabelo comęou a mexer e dai foi resolvido cortar o cabelo dela, que ia rapar, e ela queria cortar em casa. E eu mesmo cortei o cabelo dela, quando eu cortei ela chorou (silêncio) ... dai eu rapei o cabelo dela... (Adônis - marido).

Percebe-se que diante do tratamento da mãe/mulher, os filhos e os pais compartilham de sentimentos comuns em relação à modificação da imagem corporal e do que esta representa para ela, embora pareça que não falem muito sobre isso. $\mathrm{Na}$ fala do marido acima, pode-se identificar que seu gesto foi de total solidariedade e também da partilha de uma perda. Ela chorou e ele, em silêncio, chorou com ela, sem lágrimas.

\section{CONSIDERAÇÕES FINAIS}

A análise dos dados possibilitou compreender que a experiência de conviver com a mãe/esposa que foi submetida à mastectomia não se limita ao evento póscirúrgico em si. Ela é um processo que não pode ser descrito e analisado isoladamente, porque os familiares assim não a percebem. $\mathrm{Na}$ verdade, este é um fato que decorre de uma seqüência de acontecimentos que vão se interligando e em cada etapa atribuindo novas percepçôes a quem os vivencia.

Neste sentido, saber do diagnóstico de câncer provoca inicialmente um forte impacto sobre todos os membros da família. Estes comungam das mesmas percepções e as reconhecem no familiar que está doente, mas têm dificuldade em lidar com elas. A partir dessas percepçóes, mudanças ocorrem no interior de cada um e na dinâmica familiar, que segundo os entrevistados, acaba contribuindo para fortalecer os laços familiares. Diante do adoecimento da mãe/mulher, pais e filhos, no decorrer do processo, procuram rever suas posturas e atitudes, modificando-se em algum aspecto a fim de apoiar quem precisa deles. Deste modo, a situação vivida mostra-se como uma forma de aproximar a família em torno de um objetivo comum: o bem estar da mãe/ mulher. O sistema familiar que se desestabiliza diante da doença grave que acomete um de seus membros, das conseqüências do tratamento cirúrgico que resultam na amputação da mama e da quimioterapia, consegue desenvolver mecanismos para reorganizar-se e encontrar uma estabilidade.

Por outro lado, esta mesma situação vivida por outras famílias tem uma repercussão distinta. Os movimentos realizados para superar as dificuldades do tratamento são ineficazes frente aos conflitos familiares que se estabelecem (e que talvez sejam potencializados). Diante da experiência, não conseguem estabilizar-se, desorganizam-se ainda mais e acabam por romper o sistema familiar definitivamente.

Estudar a dinâmica das famílias que enfrentam o adoecimento de um de seus membros, o impacto que situação desta natureza provoca no grupo familiar e as estratégias utilizadas neste processo podem constituirse em importante fonte para a compreensão do vivido e, a partir disso, efetivamente incluir a família como sujeito das açôes de cuidados.

\section{REFERÊNCIAS BIBLIOGRÁFICAS}

1. Instituto Nacional de Câncer [homepage na Internet]. Rio de Janeiro: INCA; c1996-2005 [citado em 19 Abr 2005]. Mama. Disponível em: http://www.inca.gov.br/cancer/ mama.

2. Ferreira MGR. Enfrentando a doença [monografia na Internet]. São Paulo: Samaúma; c2001 [citado em 18 Out 2003]. Disponível em: http://www.samauma.com.br/ samauma $\% 20-20$ aproximando $\% 20$ uma $\% 20$ grande $\%$ $20 \mathrm{familia} / \mathrm{CNH}$ cancer03.htm3.

3. Coberlline VL. Câncer de mama: encontro solitário com o temor do desconhecido. Rev Gauch Enferm. 2001;3(1):42-68.

4. Fernandes AFC. O câncer de mama e a repercussão na vida familiar. J SBMCE [periódico na Internet] $2002 \mathrm{Nov}$ [citado em 24 Ago 2003]. Disponível em: http:// www.sbmce.org.br/jornais 11 02.htm.

5. Von Bertalanffy L. Teoria dos Sistemas. Rio de Janeiro: Fundação Getúlio Vargas; 1976. 
6. Wright LM, Leahey M. Enfermeiras e famílias: um guia para avaliação e intervenção na família. 3a ed. São Paulo: Rocca; 2002.

7. Instituto Brasileiro de Geografia e Estatística [homepage na Internet] Rio de Janeiro: IBGE; 2000 [citado em 8 Nov 2003]. Disponível em: http://www.ibge.gov.br/cidadesat.

8. Conselho Nacional de Saúde; Ministério da Saúde. Resolução No 196 (Out 10 1996).

9. Minayo MC, organizador. Pesquisa social: teoria, método e criatividade. 11 ed. Petrópolis: Vozes; 2000.

10. Ferreira ABH. Novo Aurélio Século XXI: o dicionário da língua portuguesa. 3a ed. rev.ampl. Rio de Janeiro: Nova Fronteira; 1999.

11. Ghisolfi ES, Broilo LO, Aguiar RW. Luto e transtorno de ajustamento. In: Kapczinski F., organizadores. Emergências Psiquiátricas. Porto Alegre: Artmed; 2001. p. 185-195.
12. Simonton SM. A família e a cura. São Paulo: Summus; 1990.

13. Damião EBC, Ângelo M. A experiência da família ao conviver com a doença crônica da criança. Rev Esc Enfermagem USP. 2001;35(1):66-71 .

14. Gimenes MGG, Queiroz F. A mulher e o câncer. Campinas: Psy; 1997.

15. Silva RM, Melo EM, Rodrigues MSP. Família como suporte para a mulher em tratamento quimioterápico. Fam Saúde Desenv. 1999;1(1-2):87-96.

16. Wolf LR. Rede de suporte social da mulher mastectomizada. [dissertação]. Ribeirão Preto (SP): Universidade de São Paulo; 1996.

17. Pedrolo FT, Zago MMF. O enfrentamento dos familiares á imagem corporal alterada do laringectomia. Rev Bras Cancerol. 2002;48(1):49-56. 